\title{
Benthic Habitat Considerations for an Offshore Wind Farm Site Selection in Puerto Rico
}

\author{
Héctor M. Rodríguez, Ph.D., P.E. ${ }^{1}$, Nelson R. Gómez-Torres, Ph.D. ${ }^{1}$, and Ricardo I. Morales, BSME Student ${ }^{1}$ \\ ${ }^{1}$ Universidad del Turabo, Puerto Rico, hrodriguez183@suagm.edu, ngomez42@suagm.edu, \\ rmorales87@email.suagm.edu
}

\begin{abstract}
The high cost of energy in Puerto Rico due to its dependence on fossil fuels has become a direct burden on individuals and a critical barrier on economic development in the Island. Minimizing the dependence on fossil fuels will not only alleviate the fluctuation in energy costs but will also reduce the negative impact to environmental pollution and greenhouse effects. To that end, the Puerto Rico Electric Power Authority (PREPA) is actively seeking alternatives to increase its renewable energy portfolio. Previous researchers have already studied renewable energy alternatives and recognized that wind energy could provide a significant amount of electric power to the Island. In particular, a wind energy study developed by the National Renewable Energy Laboratory showed that the greatest potential for wind power extraction in Puerto Rico resides in the offshore region. Due to the complexity of offshore wind energy projects, multiple factors need to be considered in the site selection. This article addresses the impact to the existing benthic habitat in the eastern offshore region in the site selection for an offshore wind farm in Puerto Rico. The approach takes advantage of an existing benthic habitat map to identify potential wind farm locations that would avoid to impact protected benthos in the region. As shown in the results, there are several locations in the eastern offshore region that could be used as a site for a wind farm with minimum impact to protected benthos.
\end{abstract}

Keywords - energy, wind, offshore, benthic habitat.

Digital Object Identifier

(DOI):http://dx.doi.org/10.18687/LACCEI2016.1.1.259

ISBN: 978-0-9822896-9-3

ISSN: 2414-6390

$14^{\text {th }}$ LACCEI International Multi-Conference for Engineering, Education, and Technology: "Engineering Innovations for Global Sustainability”, 20-22 July 2016, San José, Costa Rica. 


\title{
Benthic Habitat Considerations for an Offshore Wind Farm Site Selection in Puerto Rico
}

\author{
Héctor M. Rodríguez, Ph.D., P.E. ${ }^{1}$, Nelson R. Gómez-Torres, Ph.D. ${ }^{1}$, and Ricardo I. Morales, BSME Student ${ }^{1}$
}

${ }^{1}$ Universidad del Turabo, Puerto Rico, hrodriguez183@suagm.edu, ngomez42@suagm.edu, rmorales87@email.suagm.edu

\begin{abstract}
The high cost of energy in Puerto Rico due to its dependence on fossil fuels has become a direct burden on individuals and a critical barrier on economic development in the Island. Minimizing the dependence on fossil fuels will not only alleviate the fluctuation in energy costs but will also reduce the negative impact to environmental pollution and greenhouse effects. To that end, the Puerto Rico Electric Power Authority (PREPA) is actively seeking alternatives to increase its renewable energy portfolio. Previous researchers have already studied renewable energy alternatives and recognized that wind energy could provide a significant amount of electric power to the Island. In particular, a wind energy study developed by the National Renewable Energy Laboratory showed that the greatest potential for wind power extraction in Puerto Rico resides in the offshore region. Due to the complexity of offshore wind energy projects, multiple factors need to be considered in the site selection. This article addresses the impact to the existing benthic habitat in the eastern offshore region in the site selection for an offshore wind farm in Puerto Rico. The approach takes advantage of an existing benthic habitat map to identify potential wind farm locations that would avoid to impact protected benthos in the region. As shown in the results, there are several locations in the eastern offshore region that could be used as a site for a wind farm with minimum impact to protected benthos.
\end{abstract}

Keywords - energy, wind, offshore, benthic habitat.

\section{INTRODUCTION}

Puerto Rico (PR) is experiencing an energy crisis. PR is highly dependent on fossil fuels and therefore dependent on the whims of the fuel market. The high cost of energy is hindering the economic development of the Island. According Puerto Rico Electric Power Authority (PREPA), fossil fuels produce $99 \%$ of the electricity in PR. Only $1 \%$ of the electricity is being produced by renewable sources (see Fig. 1 for the details) [1].

Reducing the dependence on fossil fuels (reducing its market share at least) has benefits to the environment. Act no. 82 of 2010 (PR law) requires that $12 \%$ of the energy produced must be generated through renewable sources by 2015 and increases progressively to $20 \%$ by 2035 [2]. The share of electricity generated by renewable sources falls quite short of the 2015-goal set by Act no. 82 (1\% vs 12\%).

Some examples of renewable energy sources are solar, wind, nuclear, hydroelectric, bioenergy, and geothermal. Renewable energy sources are not necessarily low cost, and unfortunately, it has front-loaded costs. PREPA is trying to produce over 1,640 MW of electrical power from renewable sources [1]. Over $380 \mathrm{MW}$ of the 1,640 MW are expected to be generated from wind sources. The most significant wind

Digital Object Identifier (DOI): http://dx.doi.org/10.18687/LACCEI2016.1.1.259 ISBN: 978-0-9822896-9-3

ISSN: $2414-6390$ energy farms are in Santa Isabel and Naguabo, PR producing $75 \mathrm{MW}$ and 23MW, respectively.

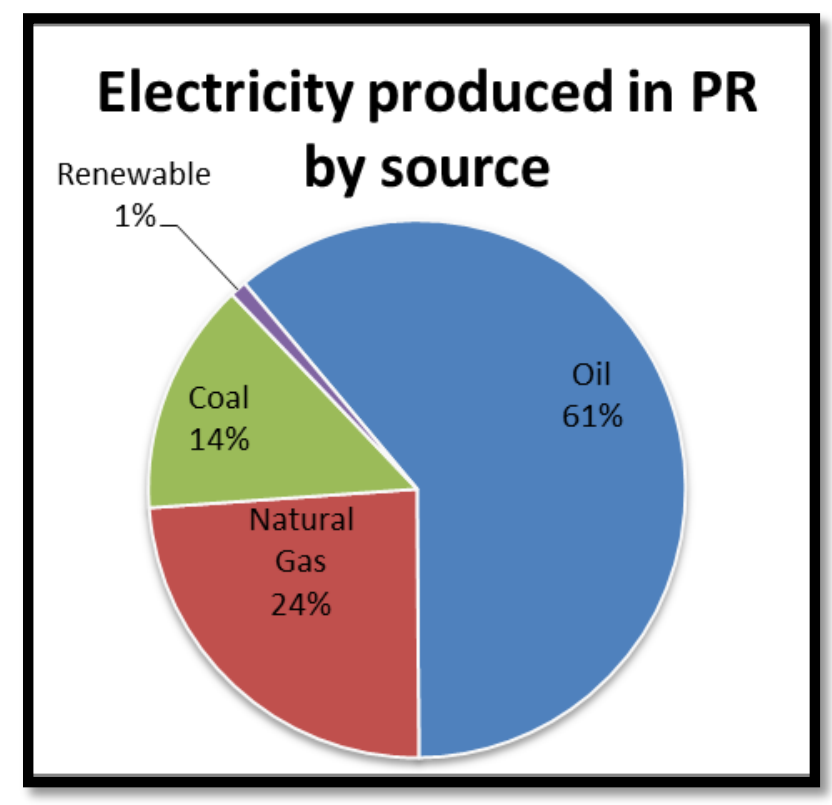

Fig. 1 Electricity produced in PR by source

Wind farms have received opposition by self-identified environmentalists groups. The environmental impact of wind generators may include: avian interaction with the wind turbines, the visual impacts (aesthetics), the noise the turbine produces, electromagnetic interference, and land effects like building over fertile ground for farming or harming the fauna environment [3]. Offshore wind turbines are becoming viable option to wind energy installations. The reduced availability of land resources on densely populated areas and increased wind energy availability in the ocean has pushed the development of these projects towards offshore regions. Offshore wind farms have become extremely attractive due to several factors such as: (1) large available area with limited environmental impact, (2) relatively higher mean wind speeds, (3) lower wind shear, (4) lower wind turbulence effects, and in many cases (5) closer proximity to high population regions [4].

The increasing trend to consider offshore wind energy systems is driven by the improved wind resource conditions far from the shore. Offshore provides vast open spaces, reduced impact on the environment, and higher energy densities [3]. Incidentally, according to a wind resource study developed by the National Renewable Energy Laboratory (NREL), the greatest potential for wind power extraction in $\mathrm{PR}$ resides

14 ${ }^{\text {th }}$ LACCEI International Multi-Conference for Engineering, Education, and Technology: "Engineering Innovations for Global Sustainability", 20-22 July 2016, San José, Costa Rica. 
offshore [5]. As shown in the study, the best wind resources in $\mathrm{PR}$ are in the northern and eastern ocean areas.

The benefits of offshore wind energy in PR were previously recognized in a University of Puerto Rico study in 2008 [6]. The study presented a preliminary assessment of offshore wind energy potential and concluded that offshore wind energy could provide more than $13,700 \mathrm{MW}$ of power. According to the study, even if only $10 \%$ of the available potential is used, offshore wind energy could produce over 2,600,000 MWh per year (i.e., enough energy to supply electricity to over 272,000 residential customers). A similar study considered a specific site in the eastern side of the Island with wind speeds in the 7.0-7.5 m/s range and shallow waters in the range 14 to 17 meters in depth [7].

A previous work considered a detailed analysis of the Levelized Cost of Energy ( $L C O E$ ) for offshore wind energy in the eastern portion of Puerto Rico [8]. According to the results, the $L C O E$ for an offshore wind energy installation will be in the $\$ 0.20 / \mathrm{kWh}-\$ 0.36 / \mathrm{kWh}$ range. Although the analysis indicated that the expected end cost of energy due to offshore wind energy production in Puerto Rico could reach a value similar to the cost of energy in the Island, the potential of offshore wind energy as a long term alternative is still attractive considering the recent interest of the U.S. in developing the offshore wind energy industry. The DOE's strategic roadmap for offshore wind energy seeks to develop an offshore wind industry able to achieve $10 \mathrm{GW}$ of offshore wind energy at a cost of energy of $\$ 0.10 / \mathrm{kWh}$ by the year 2020 and over $50 \mathrm{GW}$ at a cost of energy of $\$ 0.07 / \mathrm{kWh}$ by the year 2030 [9]. Therefore, offshore wind energy may become a viable alternative in the next decade in Puerto Rico.

In addition to the economic considerations, it is extremely important to also consider the environmental impact of the proposed wind energy project to the existing site conditions. Wind energy systems have both positive and negative environmental impacts. On the positive side, wind energy provides an alternative to avoid emissions that are typically present in large-scale conventional generation power plants. When compared to those systems the levels of emissions from the fabrication, erection and operation of wind energy systems is significantly less than conventional power plants. The main potential negative impacts of wind energy systems can be divided in terms of (1) avian/bat interaction, (2) visual impact, (3) noise, (4) electromagnetic interference, (5) shadow flicker, and (6) flora and fauna [3]. Of those potential negative impacts, the effect on flora and fauna in the offshore region of Puerto Rico will be critical for the selection of the appropriate site for wind turbine. This paper addresses the selection for a potential location to establish a wind farm in the ocean in the eastern offshore region in Puerto Rico considering the impact to existing benthic habitats in the Island. The approach takes advantage of an existing benthic habitat map to identify potential wind farm locations that would avoid to impact protected benthos in the region. As shown in the results, there are several locations in the eastern offshore region that could be used as a site for a wind farm with minimum impact to protected benthos.

\section{WIND FARM SITE SELECTION CRITERIA}

The approach taken in this investigation is to consider potential wind farm sites and then compared them in terms of (1) potential wind energy production, (2) water depth, and (3) the benthic condition. Each of these considerations are further explained as follows:

\section{A. Wind Energy Production}

The potential wind energy production considers the wind resource assessment discussed by Elliot in "Puerto Rico Wind Resources" [5]. The study was part of a collaborative effort between the DOE/NREL Wind Powering America Program, AWS Truewind and the Commonwealth of Puerto Rico. The study considered a comprehensive modeling and validation process that led to the development of detailed wind resource maps with a special resolution of $200 \mathrm{~m}$. The modeling component included the use of a numerical weather model with climatic data and a wind flow model to produce preliminary maps. The preliminary maps were validated to determine $50-\mathrm{m}$ annual average wind resource maps using available high quality data. The final maps were the result of a revision of the preliminary maps with the validation results. The study also included 70-m and 100-m maps that were extrapolated from the validated 50-m maps. Besides showing wind resource maps with average wind speeds at different heights, the study concluded that Weibull shape factors in PR are in the range of $k=2.5$ to $k=3.5$. Fig. 2 and Fig. 3 show the wind speed maps at 70-m and 100-m. As shown in Fig. 2, offshore wind speeds were estimated in the $7.0 \mathrm{~m} / \mathrm{s}$ to $9.0 \mathrm{~m} / \mathrm{s}$ range at a $70-\mathrm{m}$ height. Fig. 3 shows even better average wind speeds at 100-m height.

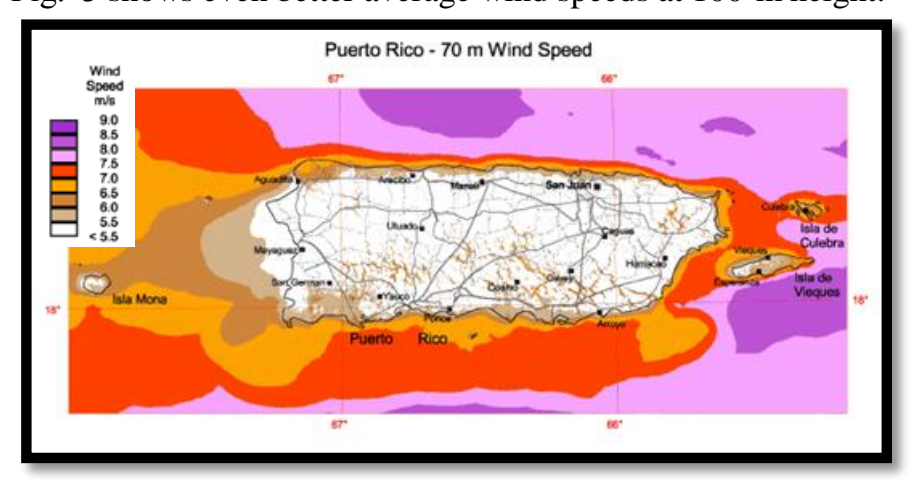

Fig. 2 Wind speed map at 70-m [5]

Typical offshore wind turbines are placed at 90-m height. In the analysis, the maps for wind speeds at 70-m height will be used to extrapolate to a $90-\mathrm{m}$ hub height (i.e., typical for offshore wind energy applications) using the power law [3] with

Digital Object Identifier: (to be inserted by LACCEI).

14 ${ }^{\text {th }}$ LACCEI International Multi-Conference for Engineering, Education, and Technology: "Engineering Innovations for Global Sustainability”, 20-22 July 2016, San José, Costa Rica. 
a wind shear exponent $\alpha=0.14$ as recommended for normal offshore operation [10].

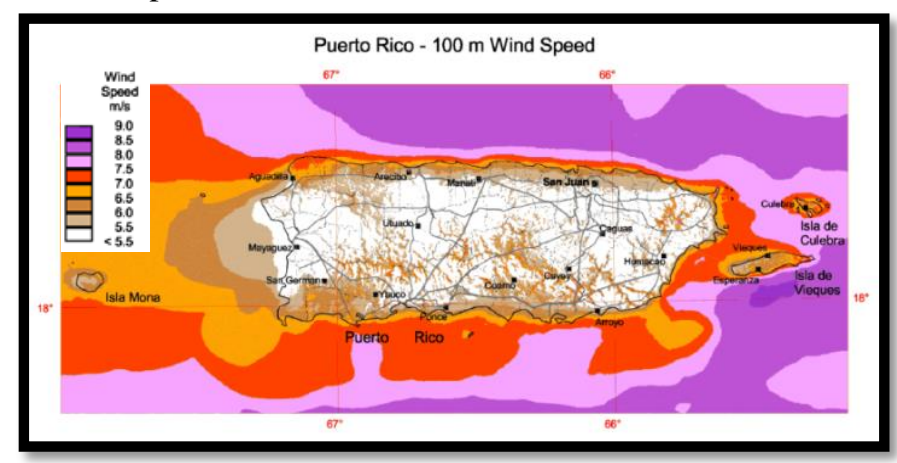

Fig. 3 Wind speed map at 100-m [5]

\section{B. Water Depth}

Current offshore wind turbine technology requires the turbines to be placed in relatively shallow waters. Typical offshore wind turbine configurations are shown in Fig. 4. As shown in the figure, existing technology is available for turbines to be placed in waters less than 30-m deep. Therefore, the potential sites to be considered in the study will be in areas where the water depth is less than 30-m. Fig. 5 shows a modified map with the $70-\mathrm{m}$ wind speed date that only considers the shallow water region in the surroundings of PR [8]. The wind speed contours in the figure are for the water region that has a depth less than or equal than $30-\mathrm{m}$. In particular, the contoured area in the eastern offshore portion of the Island (i.e., in the ocean area within the main island and the smaller islands Vieques and Culebra) comprehends approximately $900 \mathrm{~km}^{2}$.

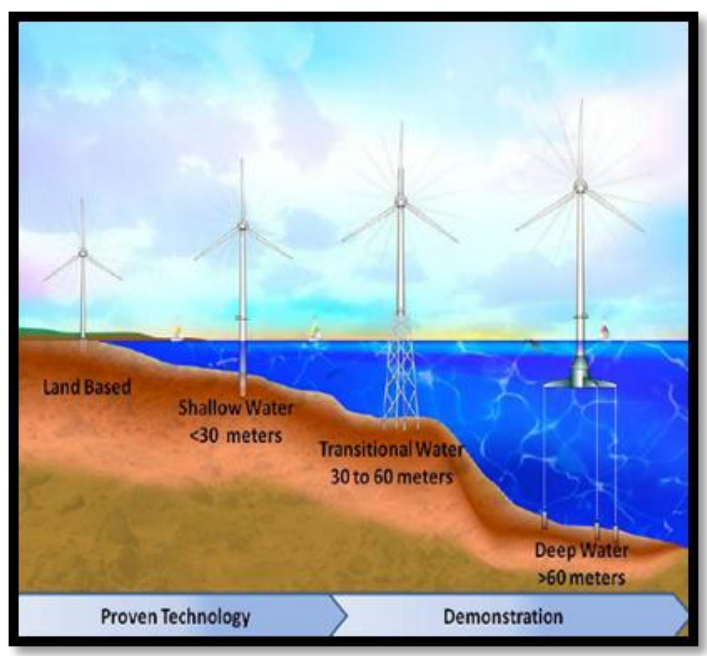

Fig. 4 Status of the Offshore Wind Energy Technology [13]

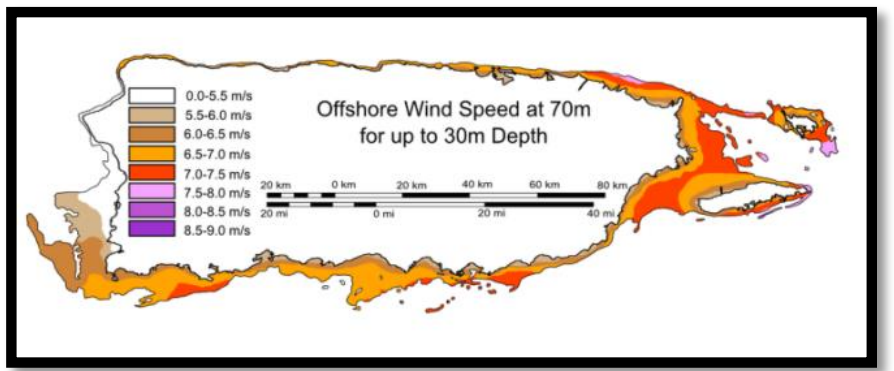

Fig. 5 Offshore 70-m wind resource map in the shallow region [8]

\section{Benthic Conditions}

Finally, it is important to consider the benthic conditions in the proposed wind farm site. The term benthic refers to anything associated with or occurring on the bottom of a body of water. The animals and plants that live on or in the bottom are known as the benthos. This paper considers benthic habitat maps developed by the National Oceanic and Atmospheric Administration (NOAA) for the Puerto Rico and the U.S. Virgin Islands [11]. Benthic habitat maps are derived from aerial imagery, underwater photos, acoustic surveys, and data gathered from sediment samples. The study (made by NOAA) [11] includes twenty-six benthic habitat types that include coral reefs, seagrass beds, mangrove forests, and other important habitats. In particular, coral reefs and mangroves should be protected and any construction, including the placement of wind turbines, should be avoided. Sea grass supplies food to herbivorous population provides large amounts of detritus which provides a major energy input for other coastal ecosystems, and their roots binds sediments together which reduces erosion [12]. Due to their rapid growth rate, sea grass beds will not be considered as restricted in this study. Coral reefs are used as the homes of a very large range of marine animal life. Since they are susceptible to any type of change in their ecosystem, they are protected by law and cannot be tampered with. Construction companies, fishermen, and any other person can receive a fine for damaging these protected reefs. Coral reefs are very sensitive to water temperatures and are affected by global warming consequences such $\mathrm{pH}$ level changes and the rise of ocean level. Hurricanes and cyclones causes devastating physical damage towards the coral reefs and there have been reports of fragmentation and uprooting of corals and sponges [13]. One of the benefits of constructing the offshore wind turbines, is that they prevent fishermen from fishing in the area and marine vegetation are known to grow around the foundation of the wind generators [14].

The benthic habitat maps are organized in numbered locations as shown in Fig. 6 [11]. Each location has an approximate area of $27.6 \mathrm{~km}^{2}$. 


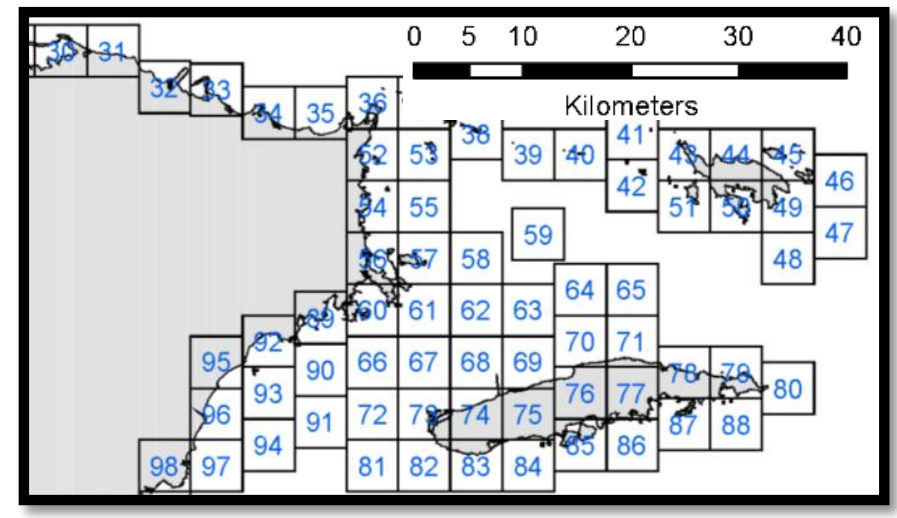

Fig. 6 Areas considered in benthic study [11]

Based on the results shown in Fig. 5, the present study considers the benthic conditions in the eastern offshore portion of the PR (i.e., the area between the eastern side of the main Island, Vieques, and Culebra). To that end, we will consider the locations identified with the numbers $60,61,62,63,64,66$, $67,68,69,70,72,73,89$, and 90 . The analysis regarding the benthic condition considers an estimate of the area within the location that has either coral reefs or mangrove beds to designate the percentage within the location that is protected. For example, location 62 is shown in Fig. 7. The area is estimated using a 10x10 quadrille on top of each location. As shown in the figure, this location has an approximate $22 \%$ of protected area.

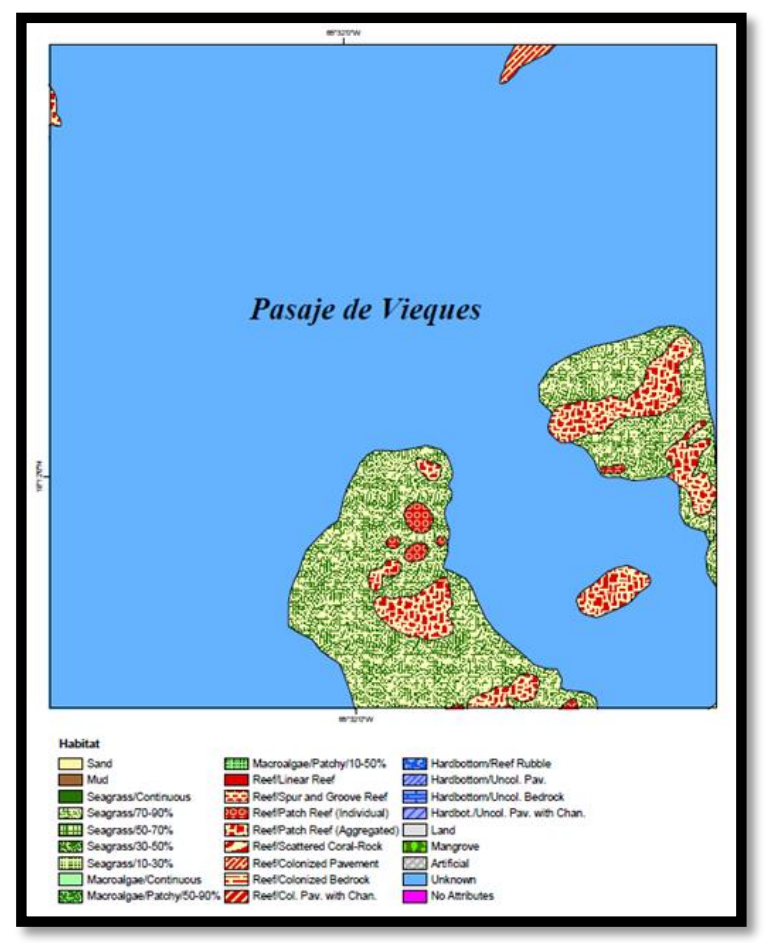

Fig. 7 Benthic conditions for location 62 [11]

\section{RESULTS}

The analysis for the best offshore location is performed using Fig. 6. Only locations that are less than $30-\mathrm{m}$ in depth, as shown in Fig. 5, are considered in the analysis. Therefore, the assessment initiates with an estimate of the average wind speed using the map in Fig. 5. Since the contours show wind speeds using ranges of $0.5 \mathrm{~m} / \mathrm{s}$, the analysis will consider an average within the range. Therefore, if a location is in the orange contour, the taken wind speed will be $7.25 \mathrm{~m} / \mathrm{s}$ and then extrapolated to a $90 \mathrm{~m}$ height (over mean sea level) using the Power Law as explained in the previous section. TABLE I shows the results for the average wind speeds at $90 \mathrm{~m}$ over Mean Sea Level (MSL) per studied location.

TABLE I

AVERAGE WIND SPEEDS AT 90 M ELEVATION OVER MSL

\begin{tabular}{|c|c|c|c|}
\hline \multirow{3}{*}{ Location } & $\begin{array}{c}\text { Wind Speed } \\
\text { according to } \\
\text { Fig. 5 }(\mathrm{m} / \mathrm{s})\end{array}$ & $\begin{array}{c}\text { A verage } \\
\text { Wind Speed } \\
\text { at } \\
(\mathrm{m} / \mathrm{s})\end{array}$ & $\begin{array}{c}\text { A verage } \\
\text { Wind Speed } \\
\text { at } 90 \mathrm{~m} \\
(\mathrm{~m} / \mathrm{s})\end{array}$ \\
\hline 60 & $6.0-6.5$ & 6.25 & 6.5 \\
\hline 61 & $6.5-7.0$ & 6.75 & 7.0 \\
\hline 62 & $7.0-7.5$ & 7.25 & 7.5 \\
\hline 63 & $7.0-7.5$ & 7.25 & 7.5 \\
\hline 64 & $7.0-7.5$ & 7.25 & 7.5 \\
\hline 66 & $6.5-7.0$ & 6.75 & 7.0 \\
\hline 67 & $6.5-8.0$ & 6.75 & 7.0 \\
\hline 68 & $6.0-6.5$ & 6.25 & 6.5 \\
\hline 69 & $6.0-6.5$ & 6.25 & 6.5 \\
\hline 70 & $6.5-7.0$ & 6.75 & 7.0 \\
\hline 72 & $6.5-7.0$ & 6.75 & 7.0 \\
\hline 73 & $6.0-6.5$ & 6.25 & 6.5 \\
\hline 89 & $6.0-6.5$ & 6.25 & 6.5 \\
\hline 90 & $6.5-7.0$ & 6.75 & 7.0 \\
\hline
\end{tabular}

The wind speed information at an assumed hub height of $90 \mathrm{~m}$ over MSL is combined with a power curve to estimate the energy production. To simplify the analysis, a typical $2.3 \mathrm{MW}$ wind turbine is assumed to be used. The analysis also assumed a typical rotor diameter of $110 \mathrm{~m}$. This rotor diameter is used to estimate the footprint for each turbine within a wind farm. Considering a crosswind spacing of $3 D$ and a downwind spacing of $10 D$, the footprint for each turbine will be 0.363 $\mathrm{km}^{2} /$ turbine. The footprint calculation is used to estimate the number of turbines and hence the total energy production in a given wind farm area. The benthic maps (i.e., such as the one shown in Fig. 7) are used to estimate the percentage of each location that has protected habitats (i.e., coral reefs or mangroves). The estimate is performed by placing a quadrille on each location as explained in the previous section. The percentage of protected area is used to estimate the available area within each location. This available area is used to estimate the total estimated energy production. TABLE II shows the number of wind turbines that fit in each location, but

14 ${ }^{\text {th }}$ LACCEI International Multi-Conference for Engineering, Education, and Technology: "Engineering Innovations for 
includes the percentage of protected zones and the available area in each location.

TABLE II

Number of turbines per location

\begin{tabular}{|c|c|c|c|}
\hline \multicolumn{4}{|c|}{ Number of turbines per location } \\
\hline 60 & $\begin{array}{c}\text { Protected } \\
\text { Zone }(\%)\end{array}$ & $\begin{array}{c}\text { A vailable } \\
\text { Area }\left(\mathrm{km}^{2}\right)\end{array}$ & $\begin{array}{c}\text { Number of } \\
\text { Turbines }\end{array}$ \\
\hline 61 & 10 & 8.3 & 21 \\
\hline 62 & 22 & 23.7 & 61 \\
\hline 63 & 42 & 21.5 & 56 \\
\hline 64 & 37 & 16.0 & 41 \\
\hline 66 & 20 & 17.4 & 45 \\
\hline 67 & 12 & 22.1 & 57 \\
\hline 68 & 18 & 24.3 & 63 \\
\hline 69 & 57 & 11.9 & 59 \\
\hline 70 & 37 & 17.4 & 30 \\
\hline 72 & 74 & 7.2 & 45 \\
\hline 73 & 46 & 14.9 & 38 \\
\hline 89 & 80 & 5.5 & 14 \\
\hline 90 & 68 & 8.8 & 23 \\
\hline
\end{tabular}

Fig. 8 shows a typical power curve for the assumed 2.3 MW turbine. The energy calculation for each turbine is performed as Rodríguez et al. using a Weibull shape factor $k=3.0$ (i.e., average between $k=2.5$ and $k=3.5$ ) [8].

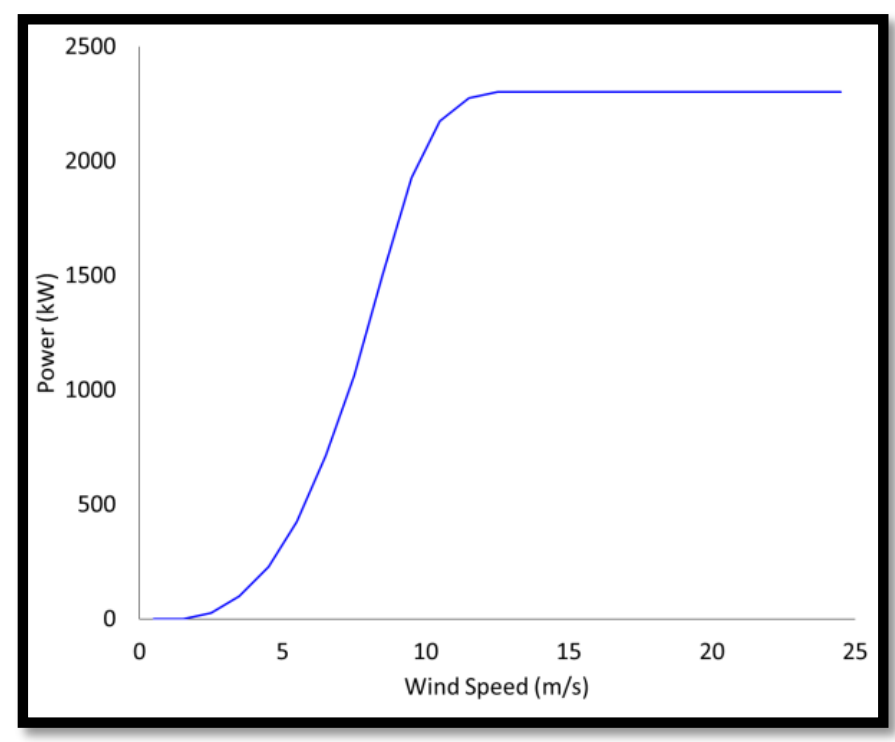

Fig. 8 Power curve for typical 2.3MW turbine

TABLE III shows the results for the studied locations. As shown in the table, the most promising areas for a wind farm correspond to locations 62, 67, and 61. All three has estimated yearly productions of over 530,000 MW-hr while minimizing the impact to the benthic habitat. The total energy production could be used to estimate the number of residential customers that could benefit from the wind farm. According to [6], an average residential customer in PR uses 9.6 MW-hr per year.
The table also includes an estimate of the number of residential customers that could benefit from offshore wind energy. In the case of the mentioned locations, over 55,000 customers could benefit from a wind farm in any of these locations.

TABLE III

Total energy that may be produced per location

\begin{tabular}{|c|c|c|c|c|}
\hline Location & $\begin{array}{l}\text { A verage } \\
\text { Wind } \\
\text { Speed } \\
\text { at } 90 \mathrm{~m} \\
(\mathrm{~m} / \mathrm{s}) \\
\end{array}$ & $\begin{array}{c}\text { Number } \\
\text { of } \\
\text { Turbines }\end{array}$ & $\begin{array}{c}\text { Yearly } \\
\text { Energy } \\
\text { per } \\
\text { Turbine } \\
\text { (MW-hr) }\end{array}$ & $\begin{array}{l}\text { Yearly } \\
\text { Total } \\
\text { Energy } \\
\text { (MW-hr) }\end{array}$ \\
\hline 60 & 6.5 & 21 & 7,490 & 157,300 \\
\hline 61 & 7.0 & 61 & $\mathbf{8 , 7 3 7}$ & 532,961 \\
\hline 62 & 7.5 & 56 & 9,923 & 555,688 \\
\hline 63 & 7.5 & 41 & 9,923 & 406,843 \\
\hline 64 & 7.5 & 45 & 9,923 & 446,535 \\
\hline 66 & 7.0 & 57 & 8,737 & 498,013 \\
\hline 67 & 7.0 & 63 & 8,737 & 550,435 \\
\hline 68 & 6.5 & 59 & 7,490 & 441,939 \\
\hline 69 & 6.5 & 30 & 7,490 & 224,715 \\
\hline 70 & 7.0 & 45 & 8,737 & 393,168 \\
\hline 72 & 7.0 & 18 & 8,737 & 157,267 \\
\hline 73 & 6.5 & 38 & 7,490 & 284,639 \\
\hline 89 & 6.5 & 14 & 7,490 & 104,867 \\
\hline 90 & 7.0 & 23 & 8,737 & 200,952 \\
\hline
\end{tabular}

Fig. 9 shows the expected energy production of each location (in GW-hr/Yr and scaled with the diameter of each bubble) plotted over a grid formed with the average depth in meters and the amount of turbines per location. Although the overall requirement to install a turbine is to be less than $30-\mathrm{m}$ depth, a further analysis could be done in terms of the tradeoff between energy production and the relative cost between water depths per turbine.

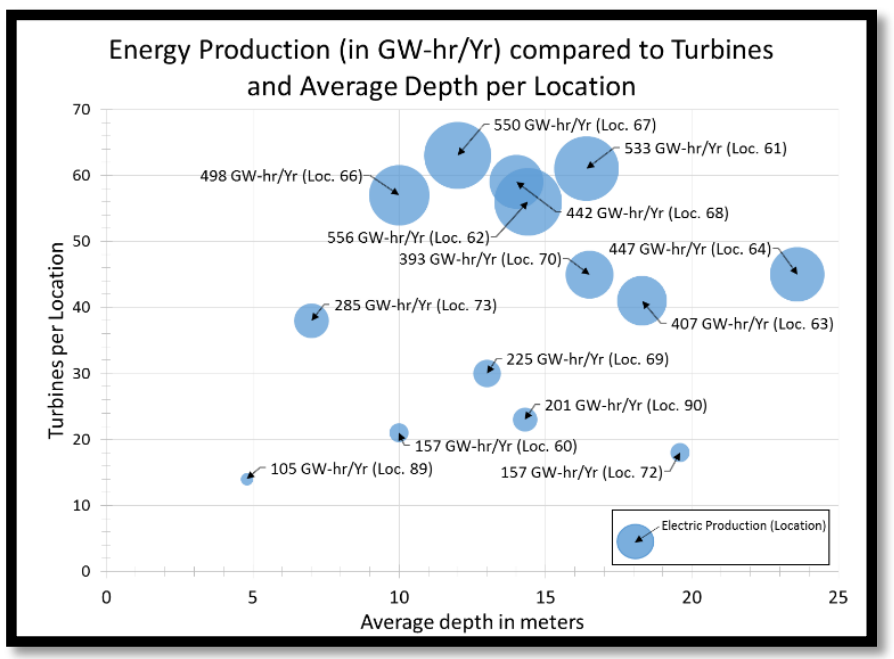

Fig. 9 Energy production

14 ${ }^{\text {th }}$ LACCEI International Multi-Conference for Engineering, Education, and Technology: "Engineering Innovations for Global Sustainability", 20-22 July 2016, San José, Costa Rica. 
In Fig. 9, locations such as 66, 73 or 89 show possible locations that may reduce construction cost. Location 66 has large electricity production capacity while reducing the depth. Location 73 has a lower electricity production capacity, but a lower depth with less turbines. Location 89 will utilize less turbines (14) and has a depth of less than $5 \mathrm{~m}$, while still producing $105 \mathrm{GW}-\mathrm{hr} / \mathrm{Yr}$.

\section{CONCLUSIONS}

Wind energy projects not only have to be economically viable but also need to consider environmental impacts. This article has shown an approach to determine the best location in terms of minimizing the impact to the benthic habitats in the offshore eastern region of PR. The approach takes advantage of the work done by NOAA in identifying the benthic habitats in PR. To simplify the analysis, the assessment for the best location uses the same quadrangle (i.e., area segments) that NOAA used to characterize the benthic habitats. Each location is characterized in terms of twenty-six distinct and nonoverlapping habitat types that fall into three main categories: coral reefs, mangroves and seagrass [11]. In terms of the wind farm assessment, the analysis considered coral reefs and mangroves as protected areas where a wind farm cannot be placed. The percentage of the areas within the locations with either coral reefs or mangroves was used then to estimate the available area for a wind farm.

As shown in the results, three areas (i.e., locations 61, 62, and 67) were identified as the best locations for a wind farm in terms of maximizing the electric production. As shown in the results, a wind farm in any of these locations could generate over 530,000 MW-hr per year and benefit over 55,000 residential customers in PR. However, considering the effect of depth and amount of turbines three locations may be better (i.e. locations 66, 73 and 89). The cost per offshore turbine in PT has been preliminary discussed by Rodríguez et al. [8], but the effect of depth in the costs of installing a turbine in PR need to be further studied.

\section{REFERENCES}

[1] PREPA, "Arranca el primer foro de infraestructura en el país," 30 May 2013. [Online]. Available:

http://aldia.microjuris.com/2013/05/30/arranca-elprimer-foro-de-infraestructura-en-el-pais/. [Accessed 1 September 2014].

[2] LexJuris, "LexJuris Puerto Rico," 19 July 2010. [Online]. Available: http://www.lexjuris.com/lexlex/Leyes2010/lex12010082 .htm. [Accessed 13 September 2014].

[3] J. F. Manwell, J. G. McGowan and A. L. Rogers, Wind Energy Explained: Theory, Design and Application, 2nd ed., John Wiley \& Sons, 2010.
[4] T. Burton, N. Jenkins, D. Sharpe and E. Bossanyi, Wind Energy Handbook (2nd), John Wiley \& Sons, Ltd, 2011.

[5] D. Elliott, "Puerto Rico Wind Resources," in Puerto Rico Wind Workshop, 2008.

[6] A. Irizarry, B. Colucci and E. O'Neill, "Achievable Renewable Energy Targets for Puerto Rico's Renewable Energy Portfolio Standard," Puerto Rico Energy Affairs, 2008.

[7] L. Noa and H. M. Rodríguez, "Preliminary Assessment for the Wind Harvesting in the Offshore Region of Puerto Rico," Polytechnic University of Puerto Rico, 2011.

[8] H. M. Rodríguez, G. Carbajal and E. Romero, "Preliminary Cost Assessment for Offshore Wind Energy in Puerto Rico," in XIII LACCEI International Conference on Engineering and Technologies, Santo Domingo, República Domicana, 2015.

[9] DoE, "A National Offshore Wind Strategy: Creating an Offshore Wind Energy Industry in the United States," 2011.

[10] International Electrotechnical Commission, "IEC 61400-3 Wind Turbines Part 3: Design Requirements for Offshore Wind Turbines," 2009.

[11] National Centers for Coastal Ocean Science Biogeography Program, "Benthic Habitats of the Puerto Rico and the U.S. Virgin Islands (CD-ROM)," National Oceanic and Atmospheric Administration, Silver Spring, MD, 2001.

[12] J. G. Liboy, "An Examination of the Present Condition of Seagrass Meadows in La Parguera, Puerto Rico.," 1979. [Online]. Available: http://www.aoml.noaa.gov/general/lib/CREWS/Cleo/Pu ertoRico/prpdfs/liboy-seagrass.pdf. [Accessed 27 February 2016].

[13] Carribean Coral Reef Institute, "CCRI," 25 February 2016. [Online]. Available: http://ccri.uprm.edu/media/CCRI_Website/physical_da mage.html.

[14] L. Bergström, L. Kautsky, T. Malm, R. Rosenberg, M. Wahlberg, N. Åstrand Capetillo and D. Wilhelmsson, "Effects of offshore wind farms on marine wildlife-a generalized impact assessment," Environmental Research Letters, vol. 9, no. 3, 19 March 2014.

$14^{\text {th }}$ LACCEI International Multi-Conference for Engineering, Education, and Technology: "Engineering Innovations for 